\title{
Sağlık çalışanlarının probiyotik, prebiyotik ve sinbiyotikler hakkındaki bilgi düzeyinin ve tüketim durumlarının belirlenmesi
}

\author{
Determination of the knowlege level and consumption of probiotic, prebiotic and sinbioticals on \\ healthcare prosfesional
}

\author{
(D) Beril KÖSE, D Aylin AYDIN, D Merve ÖZDEMIR, DEsen YEŞiL
}

Başkent Üniversitesi, Sağlık Bilimleri Fakültesi, Beslenme ve Diyetetik Bölümü, Ankara

\begin{abstract}
Giriş ve Amaç: Bu çalışmada, sağlık çalışanlarının probiyotik, prebiyotik ve sinbiyotikler hakındaki bilgi düzeylerini ve tüketim durumlarını saptamak amaçlanmıştır. Gereç ve Yöntem: Çalışmanın örneklemi, 2018 yılı Ocak-Mart aylarında sağlık çalışanı olan ve olmayan, 18 yaş üzeri ve en az ortaöğretim mezunu toplam 260 bireyden (130 sağlık çalışanı grubu, 130 kontrol grubu) oluşmaktadır. Verilenin toplanmasında demografik özelliklerin elde edilmesi ve probiyotik, prebiyotik, sinbiyotik hakkındaki bilgi düzeyleri ve tüketim durumlarını saptayabilmek için çoktan seçmeli ve açık uçlu soruları içeren bir anket formu uygulanmıştır. Bulgular: Katılımcılardan sağlık çalışanı olan ve olmayan bireylerin yaş ortalamaları sirasiyla $34.1 \pm 7.70$ ve $32.2 \pm 10.57 \mathrm{yll}$; beden kitle indeksi ortalamaları ise $24.1 \pm 3.70$ ve $24.1 \pm 4.50 \mathrm{~kg} / \mathrm{mz}^{\prime}$ dir. Probiyotik besin tüketen bireylerden bağışılık sistemini güçlendirdiğini düşünenlerin \%55.9'u sağlık çalışanı, \%44.1'i ise sağlık çalışanı olmayan bireylerdir $(p<0.05)$. Probiyotik besinleri, eğitim ve konferanslardan öğrenenlerin \%69.6'sı sağlık çalışanı iken \%30.4'ü sağlık çalışanı olmayan bireylerdir ( $p<0.01)$. Sağlık çalışanları ve sağlık çalışanı olmayan bireylerin probiyotik ve prebiyotik besin tüketimleri incelendiğinde iki grup arasında yoğurt, ayran, şalgam, turşu, muz, soğan, sarımsak ve kuru baklagil tüketimi arasında istatiksel açıdan önemli farklar bulunmuştur $(p<0.05)$. Probiyotik, prebiyotik ve sinbiyotiklerle ilgili çoktan seçmeli soruların cevaplarına göre;

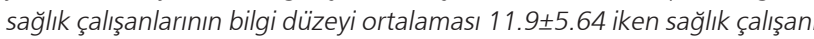
olmayan bireylerin bilgi düzeyi ortalaması $12.6 \pm 6.55$ puandır $(p>0.05)$. Sonuç: Probiyotik, prebiyotik ve sinbiyotikler konusunda sağlık çalışanı olan bireyler, kontrol grubuna göre daha düşük bilgi düzeyine sahiptir.
\end{abstract}

Anahtar kelimeler: Probiyotik, prebiyotik, sinbiyotik, sağlık çalışanları

\section{GíRiş}

"Pro" ve "biota" olmak üzere iki kısımdan oluşan probiyotik terimi yeterli miktarda verildiğinde konakçı sağlığına yarar sağlayan canlı mikroorganizmalar olarak tanımlanır $(1,2)$. Probiyotikler; patojen ve toksijenik olmama, insan kaynaklı olma, bağırsak hücre epiteline tutunabilme, antimikrobiyal özellikte salgı yapabilme, mide asidi ve safraya dirençli olma ve konakçının sağlığına olumlu katkı yapabilme gibi özelliklere sahip olarak insan sağlığı üzerinde gastrointestinal mikrobiyotayı iyileştirerek, intestinal duyarlıığı ve motilitesini etkileyerek ve lümen $\mathrm{pH}^{\prime} ı n ı$ düşürerek konstipasyonu önleyebilmektedirler (3-8). Probiyotik
Background and Aims: The aims of this study were to examine knowledge levels of probiotics, prebiotics and synbiotics and determine to consumption of healthcare prosfesional. Material and Method: The study sample was conducted in 260 participants (130 healthcare prosfesional group, 130 control group) graduated at least high school who were living Antep. They were enrolled in the study between January - May 2018. Each participant was interviewed using a structured questionnaire to obtain demographic information about education, occupation, health conditions, marital status. Also information about knowledge and consumption frequency of probiotics, prebiotics and synbiotcs notion of the participants were questioned. Results: The mean age of the healthcare and non-healthcare professionals were $34.1 \pm 7.70$ and $32.2 \pm 10.57$ years; the mean body mass index were $24.1 \pm 3.70$ and $24.1 \pm 4.50 \mathrm{~kg} / \mathrm{m} 2$. This study showed that the $\% 55.9$ of healthcare professional and \%44.1 of non-healthcare professional said that they effective on immune system $(p<0.05)$. There were statistically significant differences between the two groups in terms of consume yoghurt, ayran, turnip, pickle, banana, onion, garlic and legume. $(p<0,05)$. The mean level of knowledge probiotic, prebiotic and synbiotics of healthcare professional group was $11.9 \pm 5.64$ while the

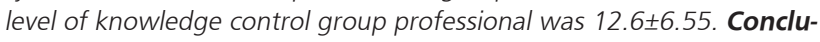
sion: Healthcare professionals had a lower level of knowledge about probiotic, prebiotic, and synbiotics than the control group.

Key words: Probiotic, prebiotic, synbiotic, healthcare professional

tüketimi biyoyararlanımının arttırıması laktoz intoleransının semptomlarının azaltılmasında da etkilidir (9).

Gibson ve arkadaşları (10) prebiyotikleri 'Bir prebiyotik konaktaki mikroorganizmalar tarafından seçici olarak kullanılan ve kanıtlanmış sağık yararı sağlayan bir maddedir.' olarak tanımlamıştır. Prebiyotikler seçici olarak fermente olabilen, gastrointestinal mikroorganizmaların kompozisyon ve/veya aktivitesini etkileyerek bireyin iyi olma hali ve sağlığı üzerinde olumlu etkileri olan besin bileşenleridir (11). 
Gibson ve Roberfroid (12), sinerjik olarak etkili olan probiyotiklerin ve prebiyotiklerin bir kombinasyonunu tanımlamak için "sinbiyotik" terimini kullanmışlardır. Sinbiyotikler hem probiyotik hem de prebiyotik özelliklere sahiptir ve gastrointestinal sistemdeki probiyotiklerin hayatta kalmasında bazı olası zorlukların üstesinden gelmek için yaratılmıştır (13). Bu nedenle, tek bir üründe her iki bileşenin uygun bir kombinasyonu, tek başına probiyotik veya prebiyotik aktivitesine kıyasla üstün bir etki sağlamalıdır (12).

Toplumda probiyotikler, prebiyotikler ve sinbiyotikler ile ilgili bilgi karmaşası bulunmaktadır. Bu terimlerin kavramları bilinmemekte ya da yanlış veya eksik bilinmektedir. Çeşitli nedenlerden ötürü geleneksel beslenme yerine özellikle hazır yiyeceklerle beslenmeye yönelimin arttığı bir çağda, besinlerin tüketimi konusunda başta sağlık çaIışanlarının dikkat etmesi ve toplumdaki diğer bireylere iyi model olmaları, rehberlik etmeleri son derece önemlidir. Ülkemizde probiyotik, prebiyotik ve sinbiyotik bilgi düzeyi ve tüketimi ile az sayıda çalışma bulunmaktadır (14).

Bu çalışma ile sağlık çalışanlarının probiyotik, prebiyotik ve sinbiyotikler hakkındaki bilgi düzeylerini saptamak ve tüketim durumlarını ölçmek amaçlanmıştır.

\section{GEREÇ ve YÖNTEM}

\section{Araştırma Yeri, Zamanı ve Örneklem Seçimi}

Bu araştırma 2018 yılı Ocak-Mart aylarında sağlık çalışanı olan ve olmayan bireyler üzerinde yapılmıştır. Araştırma örneklemini 18 yaş üzeri ve en az ortaöğretim mezunu (doktor, hemşire, ebe, laborant, anestezi teknisyeni, radyoloji teknikeri, tıbbi sekreter ve hasta bakıcı; avukat, memur, mimar, mühendis, öğrenci, öğretmen, polis, psikolog, sosyolog, emekli bireyler ve ev hanımları) 260 bireyden (130 sağlık çalışanı grubu, 130 kontrol grubu) oluşmaktadır. Araştırma öncesinde katılımcılara araştırma hakkında bilgi verilmiş ve araştırmaya katılmayı kabul eden gönüllü bireyler "Bilgilendirilmiş Olur Formu" imzalatılarak araştırmaya dahil edilmiştir. Araştırmaya sağlık çalışanlarından 56 erkek ve 74 kadın; sağlık çalışanı olmayan 51 erkek ve 79 kadın katılmışır.

\section{Verilerin Toplanması ve Değerlendirilmesi}

Katılımcılara çoktan seçmeli ve açık uçlu soruları içeren bir anket formu araştırmacı tarafından yüz yüze görüşme tekniği ile doldurulmuştur. Bu anket formu üç bölümden oluşmuştur. Birinci bölümde katılımcıların demografik özeliklerine (yaş, eğitim durumu, meslek vb.) yönelik genel bilgileri içeren sorular bulunmaktadır. İkinci bölümde katılımcılar için araştırmacılar tarafından hazırlanan, sıklıkla tüketilen probiyotik ve prebiyotik besinlerin yer aldığı besin tüketim sıklığı formu kullanılmıştır. Üçüncü bölümde ise probiyotik-prebiyotik-sinbiyotiklerle ilgili bilgi düzeyi ölçmek amacıyla çoktan seçmeli 25 soru sorulmuştur. Soruların doğru yanıtları 'bir (1)', yanlış yanıtları 'sıfır (0)'olarak puanlandırımışır.

\section{Antropometrik Ölçümler}

Araştırma kapsamına alınan bireylerin boy uzunlukları ve vücut ağırlıkları anket formuna kaydedilmiştir. Antropometrik ölçümler, araştırmacının kendisi tarafından yapımıştır. Bireylerin boy uzunlukları, ayaklar yan yana ve baş Frankfurt düzlemde (göz üçgeni ve kulak kepçesi üstü aynı hizada yere paralel) iken Scale Dr- Mod.85 marka boy ölçer ile ölçülmüştür. Bireylerin ağırlık ölçümleri, hafif giysili, ayakkabıları ve çorapları çıkartılarak TANITA BC 418 MA ile yapılmıştır. Vücut ağırlığının, boy uzunluğunun metre karesine bölünmesi [vücut ağıllığl $(\mathrm{kg}) /$ boy $^{2}$ $(\mathrm{m})$ ] ile hastaların beden kitle indeksi (BKi) hesaplanmıştır. Dünya Sağlık Örgütü (DSÖ) standartlarına göre $\geq 18.5$ - $<24.9 \mathrm{~kg} / \mathrm{m}^{2}$ normal, $\geq 25.0$ - $<29.9 \mathrm{~kg} / \mathrm{m}^{2}$ hafif şişman, $\geq 30.00 \mathrm{~kg} / \mathrm{m} 2$ ise obez olarak tanımlanmıştır (Tablo 1) (15).

\section{İstatistiksel Analiz}

Verilerin istatistiksel değerlendirilmesinde ve tabloların oluturulması amacıyla SPSS (Statistical Package for Social Sciences) 22.0 istatistik paket programı kullanılmıştır. Ölçümle elde edilen sürekli değişkenler (nicel değişkenler) için ortalama ve standart sapma değerleri kullanılmıştır. Kategorik değişkenler (nitel değişkenler) için ise frekans ve yüzde değerler kullanılmıştır. Ayrıca, kategorik değişkenlerin değerlendirilmesinde ki-kare (x2) testi kullanılmıştır. İki grubun karşılaştırıması amacıyla Mann-Whitney U testi kullanılmıştır. Değişkenler arasındaki ilişki Spearman korelasyon testi ile araştııımıştır. Analizler sonucu $p<0.05$ ve $p<0.01$ önemli olarak kabul edilmiştir.

\section{BULGULAR}

Araştırmaya, sağlık çalışanı 74 kadın ve 56 erkek, sağlık çalışanı olmayan 79 kadın ve 51 erkek olmak üzere toplam 260 kişi katılmıştır. Bireylerin yaş ve BKi ortalamaları ve standart sapmaları, cinsiyet ve eğitim durumlarının dağlımları Tablo 1'de gösterilmiştir.

Probiyotik besin tüketenlerin \%47.3'ü sağlık çalışanıdır. Probiyotik besin tüketen bireylerden bu besinlerin bağışılık sistemini güçlendirdiğini düşünenlerin \%55.9'u sağlık çalışanı iken, \%44.1'i ise sağlık çalışanı olmayan bireylerdir. Probiyotik besin tüketmeyenlerin \%60.8'i sağlık çaış̧anıdır. Probiyotik besinleri, eğitim ve konferanslardan öğrenenlerin \%69.6'sı sağlık çalışanı iken \%30.4'ü sağlık çalışanı olmayan bireylerdir (Tablo 2). 
Tablo 1. Bireylerin yaş ve BKi ortalamaları ve standart sapmaları, cinsiyet ve eğitim durumlarının dağıIımları

\begin{tabular}{|c|c|c|c|c|}
\hline & \multicolumn{2}{|c|}{$\begin{array}{l}\text { Sağlık Çalışanları Grubu } \\
\qquad \begin{array}{c}(n=130) \\
(X \pm S S)\end{array}\end{array}$} & \multicolumn{2}{|c|}{$\begin{array}{c}\text { Kontrol Grubu } \\
(n=130) \\
(X \pm S S)\end{array}$} \\
\hline Yaş (yıl) & \multicolumn{2}{|c|}{$34.1 \pm 7.70$} & \multicolumn{2}{|c|}{$32.2 \pm 10.57$} \\
\hline \multirow[t]{2}{*}{ BKI $\left(\mathrm{kg} / \mathrm{m}^{2}\right)$} & \multicolumn{2}{|c|}{$24.1 \pm 3.70$} & \multicolumn{2}{|c|}{$24.1 \pm 4.50$} \\
\hline & $\mathrm{n}$ & $\%$ & $n$ & $\%$ \\
\hline \multicolumn{5}{|l|}{ Cinsiyet } \\
\hline Kadın & 74 & 48.4 & 79 & 51.6 \\
\hline Erkek & 56 & 52.3 & 51 & 47.7 \\
\hline \multicolumn{5}{|l|}{ Öğrenim Durumu } \\
\hline Ortaöğretim & 20 & 42.6 & 27 & 57.4 \\
\hline Lisans & 102 & 53.7 & 88 & 46.3 \\
\hline Yüksek lisans & 8 & 34.8 & 15 & 65.2 \\
\hline
\end{tabular}

Tablo 2. Probiyotik besinlerin tüketim durumu ve bilgi durumu

\begin{tabular}{|c|c|c|c|c|}
\hline & \multicolumn{2}{|c|}{$\begin{array}{l}\text { Sağlık Çalışanları Grubu } \\
\qquad(n=130)\end{array}$} & \multicolumn{2}{|c|}{$\begin{array}{c}\text { Kontrol Grubu } \\
(n=130)\end{array}$} \\
\hline & $\mathbf{n}$ & $\%$ & $\mathbf{n}$ & $\%$ \\
\hline \multicolumn{5}{|l|}{ Probiyotik besin tüketimi } \\
\hline Tüketenler & 79 & 47.3 & 88 & 52.7 \\
\hline Tüketmeyenler & 51 & 54.8 & 42 & 45.2 \\
\hline \multicolumn{5}{|l|}{ Probiyotik besin tüketim nedenleri } \\
\hline Sindirim sistemine faydalı & 48 & 47.5 & 53 & 52.5 \\
\hline Kansere karşı koruyucu & 23 & 52.3 & 21 & 47.7 \\
\hline Lezzetli & 29 & 39.2 & 45 & 60.8 \\
\hline Bağışı|kık sistemini güçlendirici & 52 & 55.9 & 41 & 44.1 \\
\hline \multicolumn{5}{|l|}{ Probiyotik besin tüketmeme nedenleri } \\
\hline Ne olduğunu bilmeme & 10 & 41.7 & 14 & 58.3 \\
\hline Doğal bulmama & 5 & 41.7 & 7 & 58.3 \\
\hline İhtiyaç duymama & 31 & 60.8 & 20 & 39.2 \\
\hline Pahalı bulma & 6 & 60.0 & 4 & 40.0 \\
\hline Lezzetsiz bulma & 3 & 37.5 & 5 & 62.5 \\
\hline \multicolumn{5}{|l|}{ Probiyotik besinlerin öğrenildiği kaynaklar } \\
\hline Doktor & 13 & 38.2 & 21 & 61.8 \\
\hline Diyetisyen & 18 & 45.0 & 22 & 55.0 \\
\hline Arkadaş, aile, tanıdık vs. & 37 & 41.6 & 52 & 58.4 \\
\hline Reklam, gazete, dergi, tv & 50 & 49.0 & 52 & 51.0 \\
\hline Eğitim, konferans, bilimsel toplantı & 39 & 69.6 & 17 & 30.4 \\
\hline Eczane ve satış noktaları & 5 & 29.4 & 12 & 70.6 \\
\hline Internet & 61 & 49.6 & 62 & 50.4 \\
\hline
\end{tabular}

Probiyotik ve prebiyotik besin tüketimleri incelendiğinde iki grup arasında yoğurt, ayran, şalgam, turşu, muz, so- ğan, sarımsak, ve kuru baklagil tüketimi arasında istatiksel açıdan önemli farklar bulunmuştur $(p<0.05)$ (Tablo 3). 
KÖSE ve ark.

\section{Tablo 3. Probiyotik ve prebiyotik besin tüketim durumları}

\begin{tabular}{|c|c|c|c|}
\hline & $\begin{array}{l}\text { Sağlık Çalışanları Grubu } \\
\qquad(n=130)\end{array}$ & $\begin{array}{l}\text { Kontrol Grubu } \\
\quad(n=130)\end{array}$ & $\mathbf{p}^{\mathrm{a}}$ \\
\hline & $X \pm S S$ & $X \pm S S$ & \\
\hline Süt (ml) & $50.2 \pm 58.33$ & $61.8 \pm 75.60$ & 0.85 \\
\hline Yoğurt (ml) & $149.3 \pm 92.58$ & $99.2 \pm 89.03$ & $0.00^{* *}$ \\
\hline Peynir (gr) & $27.1 \pm 10.17$ & $27.0 \pm 7.87$ & 0.28 \\
\hline Ayran (ml) & $90.3 \pm 0.88$ & $60.5 \pm 68.87$ & $0.00^{* \star}$ \\
\hline Kefir (ml) & $8.8 \pm 26.70$ & $10.4 \pm 32.84$ & 0.93 \\
\hline Dondurma (gr) & $7.9 \pm 13.27$ & $8.3 \pm 16.90$ & 0.27 \\
\hline Ekşi mayalı ekmek (gr) & $13.3 \pm 24.73$ & $11.4 \pm 25.92$ & 0.44 \\
\hline Şalgam (ml) & $14.5 \pm 31.89$ & $8.9 \pm 24.42$ & $0.00^{* \star}$ \\
\hline Sirke $(\mathrm{ml})$ & $0.9 \pm 1.43$ & $0.7 \pm 1.19$ & 0.53 \\
\hline Turşu (gr) & $21.8 \pm 21.61$ & $19.4 \pm 26.48$ & $0.01 *$ \\
\hline Boza (ml) & $4.6 \pm 16.59$ & $3.0 \pm 9.73$ & 0.87 \\
\hline Tarhana (gr) & $1.4 \pm 2.06$ & $1.1 \pm 1.81$ & 0.11 \\
\hline Muz (gr) & $31.0 \pm 27.26$ & $18.8 \pm 23.61$ & $0.00 * *$ \\
\hline Enginar (gr) & $6.2 \pm 15.06$ & $4.1 \pm 12.50$ & 0.24 \\
\hline Pırasa (gr) & $13.1 \pm 19.94$ & $11.1 \pm 18.04$ & 0.40 \\
\hline Brokoli (gr) & $5.5 \pm 9.63$ & $5.2 \pm 7.09$ & 0.42 \\
\hline Beyaz lahana (gr) & $8.5 \pm 13.56$ & $12.3 \pm 15.21$ & 0.10 \\
\hline Kırmızı lahana (gr) & $12.9 \pm 16.43$ & $12.7 \pm 21.22$ & 0.31 \\
\hline Karnabahar (gr) & $8.0 \pm 14.31$ & $6.6 \pm 11.07$ & 0.87 \\
\hline Kuşkonmaz (gr) & $4.4 \pm 14.50$ & $2.60 \pm 9.23$ & 0.14 \\
\hline Kereviz (gr) & $3.5 \pm 8.76$ & $3.3 \pm 7.49$ & 0.90 \\
\hline Yer elması (gr) & $3.8 \pm 11.78$ & $3.7 \pm 13.44$ & 0.64 \\
\hline Soğan (gr) & $55.2 \pm 36.34$ & $44.5 \pm 38.50$ & $0.02^{*}$ \\
\hline Sarımsak (gr) & $1.0 \pm 1.29$ & $0.7 \pm 1.14$ & $0.00^{* *}$ \\
\hline Bezelye (gr) & $10.5 \pm 15.93$ & $9.7 \pm 13.91$ & 0.35 \\
\hline Kuru baklagil (gr) & $8.6 \pm 8.32$ & $4.3 \pm 6.28$ & $0.00 * *$ \\
\hline Şarap (ml) & $6.5 \pm 23.02$ & $5.5 \pm 21.86$ & 0.68 \\
\hline Şeftali (gr) & $23.6 \pm 40.89$ & $16.7 \pm 28.18$ & 0.27 \\
\hline Salam (gr) & $1.3 \pm 2.36$ & $1.2 \pm 3.01$ & 0.19 \\
\hline Sucuk (gr) & $4.4 \pm 5.65$ & $3.2 \pm 5.11$ & 0.19 \\
\hline
\end{tabular}

Tüketimler arasında fark görülen bu besinleri sağlık çallşanları daha yüksek miktarda tüketmektedir. Ayrıca sağlık çalışanlarının \%2.3'ü günde 1 kez probiyotik takviyesi (2 g) kullanmaktadır. Sağlık çalışanı olmayan bireylerde bir probiyotik takviyesi kullanımı görülmemektedir.

Probiyotik, prebiyotik ve sinbiyotiklerle ilgili 25 soruluk çoktan seçmeli soruların cevaplarına göre; sağlık çalışanlarının bilgi düzeyi ortalaması $11.9 \pm 5.64$ puan iken sağlık çalışanı olmayan bireylerin bilgi düzeyi ortalaması $12.6 \pm 6.55$ puandır. Sağlık çalışanlarının bilgi düzeyi puanı; yoğurt ve muz tüketimiyle pozitif korelasyon göstermiştir (sırasıyla $r=0.118, p=0.032 ; r=0.195, p=0.026$ ).

\section{TARTIŞMA}

Günümüzde sağlıklı beslenme farkındalığının giderek artmasıly toplumsal olarak fonksiyonel besinlere ve besin 
desteklerine yönelim daha sık görülmeye başlanmıştır. Fonksiyonel besinler, temel beslenmenin yanı sıra insan fizyolojisi ve metabolik fonksiyonları üzerinde ilave faydalar sağlayan, böylelikle hastalıklardan korunmada ve daha sağIıklı bir yaşama ulaşmada etkinlik gösteren besinler olarak tanımlanmaktadır. Probiyotik, prebiyotik ve sinbiyotikler de fonksiyonel besinler içerisinde büyük yere sahiptirler (16).

Eğitim düzeyi yüksek olduğu bilinen sağlık çalışanları üzerinde yapılan çalışmalarda, probiyotiklerle ilgili bilgi düzeyinin şaşırtıcı bir şekilde düşük olduğu sonucuna varılmıştır $(17,18)$. Anukam ve ark. (17) yaptığı çalışmada Nijerya'lı sağlık çalışanlarının \%4.8'inin probiyotik terimi hakkında bilgi sahibi olduğunu, benzer şekilde Edmunds (18) tarafından yapılan çalışmada Kanada'lı sağlık çalışanlarının sadece \%18.0'inin probiyotikler hakkında bilgi sahibi oldukları belirtilmiştir. Bu araştırmada probiyotik, prebiyotik ve sinbiyotikler konusunda sağlık çalışanı olan bireyler, kontrol grubuna göre daha düşük bilgi düzeyine sahiptir. Araştırmamıza katılan bireylerde çoğunluğu lisans mezunları oluşturmaktadır. Sağlık çalışanı olmayan grubun da bilgi düzeyi puanının sağlık çalışanlarıyla benzer olmasının bu durumla ilişkilendirilebileceğini düşünmekteyiz. Çalışmamızda probiyotik terimi hakkında bilgi sahibi olan sağlık çalışanlarının sıklığı \%53.9 iken sağlık çalışanı olmayan bireylerin \%46.1'dir.

Yabancı ve Şimşek (19) tarafından yapılan çalışmada, probiyotik ürünleri tüketmeyen katılımcıların bu ürünleri tüketmeme nedeni olarak; \%43.5'i bilmediklerini, \%19.5'i doğal olmadığını düşündüklerini, \%14.9'u ihtiyaç duymadıklarını, \%12.9'u pahalı ve \%8.5'i lezzetsiz bulduklarını ifade etmişlerdir. Aydın ve ark. (20) yaptığı bir çalışmada, probiyotik ürün tüketmeyen bireylerin \%54.7'sinin bu ürünleri bilmediklerini, \%24.7'sinin ihtiyaç duymadığını, \%10.4'ünün doğal bulmadıklarını, \%5.8'inin lezzetsiz bulduğunu, \%4.4'ünün pahalı bulduğunu belirtmişlerdir. Derin ve Keskin (21) öğrenciler üzerinde yaptıkları çalışmada probiyotik ürünleri tüketmeyen öğrencilerin \%49.2'sinin bilmediğini, \%38.7'sinin ihtiyaç duymadığını, \%5.9'unun doğal bulmadığını, \%1.9'unun lezzetsiz ve \%4.3'ünün pahalı bulduğunu belirtmişlerdir. Çalışmamızdaki sağlık çalışanları ise probiyotik besin tüketmeme nedeni olarak; probiyotik besinleri bilmediklerini (\%41.7), doğal bulmadıklarını (\%41.7), ihtiyaç duymadıklarını (\%60.8), pahalı (\%60.0) ve lezzetsiz (\%37.5) bulduklarını belirtmişlerdir.

Araştırmalar, probiyotik besinlerin öğrenildiği kaynaklar yönünden ele alındığında; Yabancı ve Şimşek (19) tarafından yapılan çalışmada katılımcılardan \%79.1'inin,
Derin ve Keskin (21) tarafından yapılan çalışmada ise öğrencilerin \%31.6'sının reklamlardan etkilendiği saptanmıştır. Schultz ve ark. (22) kullanıcıların \%75.2'sinin bir öneri sonucu probiyotik kullandıklarını, \%80.5'inin ise doktorlar tarafından önerildiği takdirde bir probiyotik kullanmayı düşündüklerini belirtmişlerdir. Çalışmamızda ise reklamlardan öğrenme oranı sağlık çalışanlarında \%49.0 iken sağlık çalışanı olmayan bireylerde \%51.0'dır. Sağlık çalışanlarının \%38.2'si doktorlardan \%45.0'ı diyetisyenlerden probiyotik besinleri öğrendiğini bildirmiştir.

Anukam ve ark. (17) sağlık çalışanları üzerinde probiyotik besinlerin bilgi düzeyi hakkında yaptıkları çalışmada en çok tüketilen probiyotik besin \%45.1 oranında yoğurttur. Betz ve ark. (23) hastanede yatan hastalar üzerinde; probiyotik ve prebiyotiklerin bilgi, kullanım ve algıları hakkında yaptıkları çalışmada tüketilen en yaygın probiyotik ve prebiyotik ürünler sırasıyla yoğurt (\%72.0) ve hububat/ granola bar (\%55.0) olarak saptanmıştır. Viana ve ark. (24) tüketicilerin probiyotik besinler hakkında algı ve tutumunu gözlemledikleri bir çalışmada \%27.6 oranında süt tüketimi, \%25.7 yoğurt tüketimi ve \%13.3 peynir tüketimi olduğunu belirtmişlerdir. Diğer çalışmalardan farkIı olarak Hacıoğlu ve Kurt (25) tüketicilerin fonksiyonel besinlere karşı tutum ve farkındalıkları üzerine yaptıkları çalışmada en çok tüketilen probiyotik besinin kefir (\%41) ve yoğurt (\%26) olduğunu göstermişlerdir. Bizim araştırmamızda her iki grupta da en çok tüketilen probiyotik besin yoğurt olarak belirlenmiştir.

Oliver ve ark.'nın (26) sağlık çalışanlarının probiyotik ve prebiyotikler hakkındaki bilgi, algı ve kullanımı üzerine yaptıkları bir çalışmada probiyotiklerin bilinme durumu $\% 88.0$ iken prebiyotiklerin bilinme durumu \%22.0 oranındadır. Selanik kentinde bulunan bireyler üzerinde yapılan çalışmada; katılımcıların yalnızca \%24.0'ünün probiyotik terimi hakkında bilgi sahibi olduğu sonucuna varmışlardır (27). Bizim çalışmamızda da sağlık çalışanlarının probiyotik ve prebiyotik terimini bilme durumu sırasıyla \%73.8 ve \%26.9 iken bu durum sağlık çalışanı olmayan bireylerde sırasıyla \%63.1 ve \%37.7 sıklığındadır.

Çalışmanın sonucunda, probiyotik, prebiyotik ve sinbiyotikler konusunda sağlık çalışanı olan bireyler, kontrol grubuna göre daha düşük bilgi düzeyine sahiptir. Bu nedenle bireylerin probiyotik, prebiyotik ve sinbiyotiklerle ilgili bilgi, tutum ve davranışları konusunda eğitime ihtiyaç duydukları düşünülmektedir. Bu konuda daha kapsamlı çalışmalar planlanmalıdır. 


\section{KAYNAKLAR}

1. Coşkun T. Pro-, pre- ve sinbiyotikler. Çocuk Sağlığı ve Hastalıkları Dergisi 2006;49:128-48.

2. FAO/WHO (2002) Guidelines for the evaluation of probiotics in foods. Food and Agriculture Organization of the United Nations and World Health Organization Expert Consultation Report. Food and Agricultural Organization of the United Nations and World Health Organization Working Group Report (online).

3. Coşkun T. Fonksiyonel besinlerin sağlığımız üzerine etkileri. Çocuk Sağlığı ve Hastalıkları Dergisi 2005;48:69-84.

4. Chmielewska A, Szajewska H. Systematic review of randomised controlled trials: probiotics for functional constipation. World J Gastroenterol 2010;16:69-75.

5. Khalif IL, Quigley EM, Konovitch EA, Maximova ID. Alterations in the colonic flora and intestinal permeability and evidence of immune activation in chronic constipation. Dig Liver Dis 2005;37:83849.

6. Zoppi G, Cinquetti M, Luciano A, et al. The intestinal ecosystem in chronic functional constipation. Acta Paediatr 1998;87:836-41.

7. Ait-Belgnaoui A, Han W, Lamine F, et al. Lactobacillus farciminis treatment suppresses stress induced visceral hypersensitivity: a possible action through interaction with epithelial cell cytoskeleton contraction. Gut 2006;55:1090-4.

8. Salminen S, Salminen E. Lactulose, lactic acid bacteria, intestinal microecology and mucosal protection. Scand J Gastroenterol Suppl 1997;222:45-8.

9. Yadav $\mathrm{H}$, Jain $\mathrm{S}$, Sinha PR. Oral administration of dahi containing probiotic Lactobacillus acidophilus and Lactobacillus casei ameliorated the Streptozotocin-induced oxidative stress and dyslipidemia in rats. J Dairy Res 2008;75:189-95.

10. Gibson GR, Hutkins R, Sanders ME, et al. Expert consensus document: The International Scientific Association for Probiotics and Prebiotics (ISAPP) consensus statement on the definition and scope of prebiotics. Nat Rev Gastroenterol Hepatol 2017;14:491-502.

11. World Gastroenterology Organisation, Global Guidelines Probiotics and Prebiotics, 2017. Erişim: (http://www.worldgastroenterology. org/guidelines/global-guidelines/probiotics-and-prebiotics/probiotics-and-prebiotics-english) Erişim Tarihi: 13.5.2018.

12. Gibson GR, Roberfroid MB. Dietary modulation of the human colonic microbiota: introducing the concept of prebiotics. J Nutr 1995; 125:1401-12.

13. Rioux KP, Madsen KL, Fedorak RN. The role of enteric microflora in inflammatory bowel disease: Human and animal studies with probiotics and prebiotics. Gastroenterol Clin N Am 2005;34:465-82.
14. Karadağ G, Aydın N, Kayaaslan H. Gaziantep Üniversitesi Tıp ve Hemşirelik Bölümünde okuyan, öğrencilerin besin güvenliğine ilişkin duyarlılık ve görüşleri. TAF Prev Med Bull 2012;11:436-46.

15. Report of a WHO consultation. Obesity: Preventing and managing the global epidemic. WHO Technical Report Series. Geneva, 894, 2000. Erişim: (http://www.who.int/nutrition/publications/obesity/ WHO_TRS_894/en/) Erişim Tarihi: 27.5.2018.

16. Sevilmiş G. Yükselen trend: Fonksiyonel gıdalar. AR\&GE Bülten, İzmir Ticaret Odası 2013;39-46.

17. Anukam KC, Osazuwa EO, Reid G. Knowledge of probiotics by Nigerian clinicians. Int J Probiotics Prebiotics 2006;1:57-62.

18. Edmunds $L$. The underuse of probiotics by family physicians. CMAJ 2001;164:1577.

19. Yabancı N, Şimşek I. Üniversite öğrencilerinin probiyotik ürün tüketim durumları. TSK Koruyucu Hekimlik Bülteni 2007;6:449-54.

20. Aydın M, Açıkgöz I, Şimşek B. Isparta Süleyman Demirel Üniversitesi öğrencilerinin probiyotik ürün tüketimlerinin ve probiyotik kavramının bilinme düzeyinin belirlenmesi. Gıda Teknolojileri Elektronik Dergisi 2010;5:1-6.

21. Derin DÖ, Keskin S. Gıda mühendisliği öğrencilerinin probiyotik ürün tüketim durumlarının belirlenmesi: Ege Üniversitesi örneği. Gıda 2013;38:215-22.

22. Schultz $M$, Baranchi $A$, Thurston $L$, et al. Consumer demographics and expectations of probiotic therapy in New Zealand: results of a large telephone survey, N Z Med J 2011;124:36-43.

23. Betz M, Uzueta A, Rasmussen $H$, et al. Knowledge, use and perceptions of probiotics and prebiotics in hospitalised patients. Nutrition and Dietetics 2015;3:261-6.

24. Viana JV, Da Cruz GA, Zoellner SS, et al. Probiotic foods: consumer perception and attitudes. Int J Food Sci Technol 2008;9:1577-80.

25. Hacıoğlu G, Kurt G. Tüketicilerin fonksiyonel gıdalara yönelik farkındalığı, kabulü ve tutumları: İzmir ili örneği. Business and Economics Research Journal 2012;1:161-71.

26. Oliver L, Rasmussen $H$, Gregoire MB, et al. Health care provider's knowledge, perceptions, and use of probiotics and prebiotics. Top Clin Nutr 2014;29:139-49.

27. Babajimopoulos M, Fotiadou E, Alexandridou E, et al. Consumer's knowledge on probiotics and consumption of these products in the city of Thessaloniki, Greece. Consumer and Nutrition, Proceedings of the $9^{\text {th }}$ Karlsruhe Nutrition Congress, 2004. 